\title{
Occupational rhinitis in workers investigated for occupational asthma
}

\author{
R Castano, ${ }^{1,2}$ D Gautrin, ${ }^{1}$ G Thériault, ${ }^{1}$ C Trudeau, ${ }^{2}$ H Ghezzo, ${ }^{2}$ J-L Malo ${ }^{2}$
}

\begin{abstract}
- Additional details of the design of the study are published online only at http:// thorax.bmj.com/content/vol64/ issue1

${ }^{1}$ Department of Epidemiology, Biostatistics and Occupational Health, McGill University, Montreal, Quebec, Canada; ${ }^{2}$ Department of Chest Medicine, Hôpital du Sacré-Cœur de Montréal, Quebec, Canada
\end{abstract}

Correspondence to: Dr R Castano, Hôpital du SacréCœur de Montréal, Centre de Recherche-Pneumologie, 5400 Gouin Blvd West, Montreal, OC Canada, H4J 1C5; roberto. castano@mail.mcgill.ca

Received 7 June 2008 Accepted 29 August 2008 Published Online First 3 October 2008

\begin{abstract}
Background: The links between asthma and rhinitis are now referred to as united airways disease (UAD). Current evidence shows that the UAD model seems to be applicable to occupational rhinitis (OR) and occupational asthma (OA). A study was undertaken to objectively assess, in the context of specific inhalation challenge (SIC) testing, the concomitance of bronchial and nasal reaction in the investigation of $O R$ and $O A$.

Methods: 43 subjects with a history of work-related asthma symptoms underwent SIC for confirmation of OA and investigation of OR. Changes in bronchial calibre were measured by spirometry and nasal patency and airway inflammation were assessed by acoustic rhinometry and nasal lavage.
\end{abstract}

Results: A positive nasal challenge was observed in 25 SIC tests and a positive bronchial challenge was observed in 17 SIC tests. A concomitant positive nasal and bronchial challenge was observed in 13 instances. This association was significant (risk ratio $=1.7 ; 95 \% \mathrm{Cl} 1.0$ to 2.4; $p=0.04$ ) and more frequent in subjects challenged with high molecular weight agents $(n=11 / 22)$ than with low molecular weight agents $(n=2 / 21)$. In subjects with a positive nasal challenge, nasal lavage showed a significant increase in eosinophils 30 min after exposure which correlated with changes in nasal patency.

Conclusion: The results of this study provide objective evidence to support the concept of UAD using OR and OA as a model to demonstrate a significant concomitant physiological reaction of the nose and lungs after challenge. This study shows that OR can be assessed by objective means; it often coexists with $\mathrm{OA}$ but can be present without $\mathrm{OA}$.

Occupational asthma $(\mathrm{OA})$ is the most frequent work-related lung disease. ${ }^{1}$ As the inflammatory process in the bronchi can also affect the upper airways, the study of occupational rhinitis (OR) in conjunction with $\mathrm{OA}$ is of interest. The link between rhinitis and asthma in the general population has led to the proposed "united airways disease" (UAD) model, which also appears to be applicable to OR and OA. Rhinitis symptoms are common in subjects with OA. ${ }^{2}$ Epidemiological studies show that subjects with OR have a high risk of asthma. ${ }^{3}$ However, current evidence on the link between $O R$ and $O A$ is supported more by occupational epidemiological studies than by pathophysiological observations. ${ }^{45}$

The diagnosis of $\mathrm{OA}$ and $\mathrm{OR}$ is challenging because it entails the objective demonstration of significant changes in lung and nasal status after exposure to occupational agents in order to confirm the causal association between occupational exposure and the disease. This diagnosis can be confirmed by performing specific inhalation challenge (SIC) tests in which the worker is exposed to the suspected agent. ${ }^{6}$ This test is considered the "gold standard" for confirming OA. By contrast, there is no standardised procedure to confirm OR; however, assessment of changes in clinical and functional parameters by means of objective and subjective methods during nasal provocation testing with suspected aetiological agents is thought to represent a suitable approach for confirming OR. ${ }^{7-9}$

The aim of the present study was to assess objectively, in the context of SIC testing, the concomitance of bronchial and nasal reactions in the diagnosis of asthma and rhinitis following exposure to occupational agents. A second objective was to assess nasal changes in cellular markers of inflammation after SIC testing.

\section{METHODS}

\section{Study subjects}

The study population consisted of 43 subjects with a history suggestive of OA referred to the Hôpital du Sacré-Coeur de Montréal for SIC. Subjects were offered an evaluation of nasal responses during the SIC as an attempt to investigate OR. Evaluation of the nose was not offered if subjects (1) reported a history compatible with a recent common cold, rhinosinusitis or allergic rhinitis exacerbation; (2) were on regular medications for nasal symptoms; (3) had antecedents of recent nasal surgery; and (4) had significant structural abnormalities in their nasal cavities such as nasal septum perforation or nasal polyposis. Ethical approval for the study was obtained from the hospital medical ethics committee.

\section{Design of study}

Each SIC involved evaluating a single agent during a control day and at least one active day depending on the time of occurrence of the asthmatic reaction or when the maximum duration of exposure had been achieved in the absence of an asthmatic reaction. In most instances, subjects were assessed within the same week. Two challenge methodologies were used: (1) recreating working conditions in small cubicles; or (2) with a closed-circuit apparatus that exposes subjects to lower and stable concentrations of the suspected occupational agent. ${ }^{10}$ The rationale for selecting one method over the other as the initial procedure was the limited possibility of the closed-circuit equipment to generate the active or control agent.

The investigation of OA by SIC is a common and standardised procedure in our hospital. ${ }^{11}$ On the first day the worker is exposed for $30 \mathrm{~min}$ to a 
control inert substance similar in nature to the suspected agent in order to assess non-specific bronchial and nasal responses. The assessment of lung function involves monitoring forced expiratory volume in $1 \mathrm{~s}\left(\mathrm{FEV}_{1}\right)$ before exposure and then every $10 \mathrm{~min}$ for $1 \mathrm{~h}$, every $30 \mathrm{~min}$ for $2 \mathrm{~h}$, then hourly for a total of $8 \mathrm{~h}$. In the case of high molecular weight (HMW) agents, exposure is carried out on a single day because these products cause immediate or dual reactions. For low molecular weight (LMW) agents, the exposure is progressively increased from day to day because of the possibility of late reactions that are difficult to predict. ${ }^{12}$

As shown in fig 1, the assessment of nasal responses during SIC was carried out in parallel to the assessment of lung responses. During each SIC session nasal responses were objectively monitored by acoustic rhinometry and nasal lavage. Additional details are provided in the online supplement.

\section{Acoustic rhinometry}

A trained technician performed acoustic rhinometry according to a standardised procedure. ${ }^{13}$ An acoustic rhinometer (Hoods Laboratories, Pembroke, MA, USA) was used to measure the nasal volume $2-5 \mathrm{~cm}$ into the nose $\left(\mathrm{Vol}_{2-5}\right)$ and the minimum cross-sectional area (MCA). The $\mathrm{Vol}_{2-5}$ was selected as the main end point to better reflect mucosal changes. ${ }^{13}{ }^{14}$ Three measurements with a coefficient of variation of $\leqslant 6 \%$ were obtained for each nostril to calculate total $\mathrm{Vol}_{2-5}$ and total MCA.

\section{Nasal lavage}

The nasal lavage protocol was adapted from the procedure described by Naclerio et al. ${ }^{15}$ Briefly, the subject is instructed to avoid breathing and swallowing and to say "k-k" repeatedly for $10 \mathrm{~s}$ in order to prevent the fluid being swallowed during the nasal lavage by closing the velopharynx with this action. ${ }^{16}$ Five $\mathrm{ml}$ of isotonic saline $(0.9 \%)$ is then instilled into one nostril. After $10 \mathrm{~s}$ the subject expels the fluid into a container; the procedure is performed in the other nostril and the sample is collected and pooled in the same container and immediately placed on ice before processing. Further details are given in the online supplement.

\section{Complementary assessments}

Subjects completed a questionnaire that assessed the frequency of nasal symptoms. Atopy was assessed by skin prick test to a set of 20 allergen extracts using standard procedures. ${ }^{17}$

\section{Definition of outcomes}

Objective changes in nasal patency and bronchial calibre were the main outcomes. A decrease in $\mathrm{Vol}_{2-5}$ of $\geqslant 30 \%$ after exposure was considered a positive nasal challenge to confer a diagnosis of $\mathrm{OR}$ in the absence of a positive reaction during the control day. The threshold of $\geqslant 30 \%$ was selected from the analysis of the variability of $\mathrm{Vol}_{2-5}$ for all study subjects during their control sessions $(n=14)$ and using findings from related published studies. ${ }^{18}{ }^{19}$ A decrease in $\mathrm{FEV}_{1}$ of $\geqslant 20 \%$ after exposure was considered a positive bronchial challenge to confer a diagnosis of $\mathrm{OA}$. This is a widely accepted criterion in the literature. ${ }^{20} \mathrm{Nasal}$ lavage results and subjective nasal measurements (symptoms score and visual analogue scale) were used to support the diagnosis.

\section{Statistical analysis}

The association between nasal and bronchial parameters was compared in a contingency table by $\chi^{2}$ and Fisher exact test analysis. The strength of the association between the nasal reaction and the bronchial reaction was estimated by computing the risk ratio and $95 \%$ confidence intervals. Pearson and Spearman rank methods were used to perform correlations in parametric and non-parametric data. The Wilcoxon matched pairs signed test was used to assess within-subject changes in nasal lavage during and between days of investigation. A 5\% level of significance was applied to the statistical analysis. Statistical analyses were performed using SPSS for Windows Version 14.0 (SPSS, Chicago, Illinois, USA).

\section{RESULTS}

The initial study population consisted of 53 subjects in whom 53 control sessions were conducted. Ten subjects were excluded from the study after their control session owing to observed fluctuations in AR measurements. A negative nasal reaction to the control substance was a prerequisite to continue with the active challenge in the following days. A total of 43 SIC tests with HMW and LMW agents performed in 43 subjects were analysed.

Table 1 shows that nasal symptoms were frequent in the study population. The frequency of each nasal symptom in all subjects was above $70 \%$. However, no difference was observed in the frequency of nasal symptoms based on a final positive or negative bronchial challenge (data not shown). The frequency of all nasal symptoms was higher in the group of workers exposed to HMW agents than in those exposed to LMW agents (table 1).
Figure 1 Specific inhalation challenge (SIC) protocol: joint assessment of the nose and lungs. $\mathrm{FEV}_{1}$, forced expiratory volume in $1 \mathrm{~s}$; MCA, minimum crosssectional area; VAS, visual analogue scale.

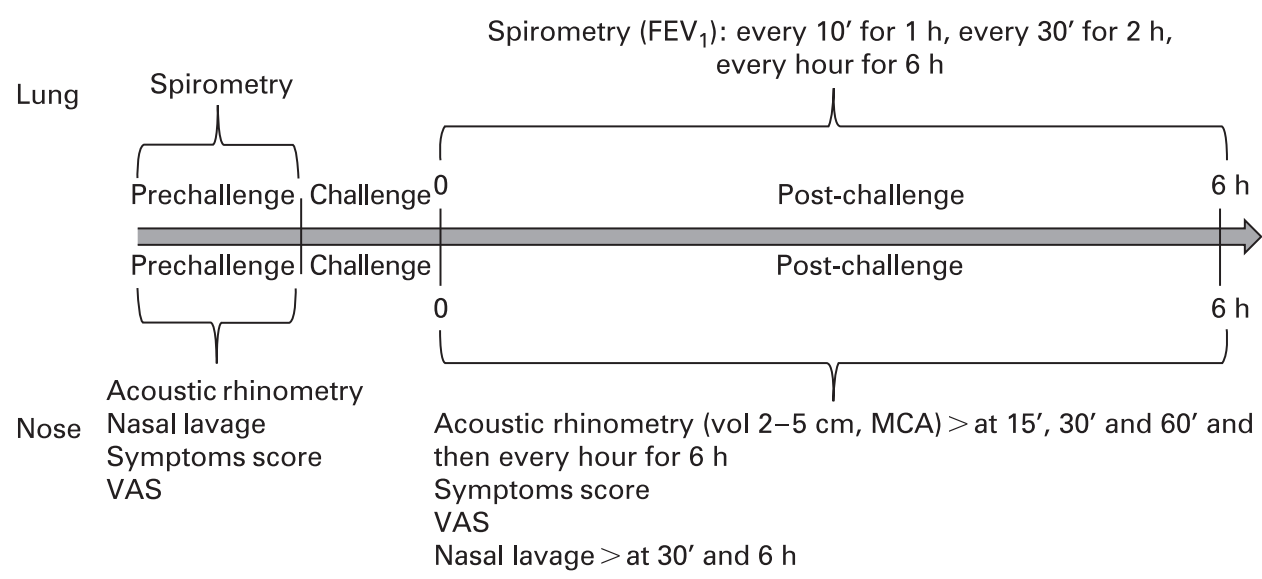




\section{Acoustic rhinometry values}

The analysis of data from all challenges showed that, on the control day of exposure, the mean (SD) maximum percentage decreases in acoustic rhinometry compared with baseline were 13.2 (8.8)\% (range 28\%) for $\mathrm{Vol}_{2-5}$ and 11.9 (8.4)\% (range 30\%) for MCA. On challenge days of exposure to the active agents, the mean (SD) maximum percentage decreases were 31.8 (16.5)\% (range 81\%) for $\mathrm{Vol}_{2-5}$ and 25.6 (16.5)\% (range $77 \%$ ) for MCA. The correlation between $\mathrm{Vol}_{2-5}$ and MCA for measuring these changes during the control day $(r=0.6$; $p<0.01)$ and on the challenge day $(r=0.9 ; p<0.01)$ was satisfactory and significant.

\section{Results of bronchial and nasal response to the challenge}

Table 2 shows the outcome of the 43 SIC included in the analysis. Among those with significant changes in bronchial calibre, most (13/17) also had significant low nasal patency. Among those with no significant low bronchial calibre, about half had significant low nasal patency $(12 / 26)$. The frequency of reported work-related nasal symptoms in this group was high (runny nose: 100\%; itching: 83\%; sneezing, 91.7\%; nasal blockage: $83.3 \%$ ); $91 \%$ of subjects in this group also reported the appearance of work-related nasal symptoms before or almost at the same time as the appearance of work-related asthma symptoms. Most (9/12) had clinically significant nasal responses to challenge with the active agent based on nasal symptom scoring.

A positive nasal challenge was observed in 25/43 SIC (58.1\%) whereas a positive bronchial challenge was observed in $17 / 43$ SIC (39.5\%). A concomitant positive nasal and bronchial challenge was observed in 13 instances (30.2\%). The estimated risk ratio (RR) shown in table 2 showed a statistically significant positive association of a moderate magnitude between these clinically significant nasal and bronchial responses ( $R R$ 1.7; 95\% CI 1.0 to $2.4 ; \mathrm{p}=0.04$ ).

Table 1 Baseline anthropometric and clinical characteristics of study subjects $(n=43)$

\begin{tabular}{|c|c|}
\hline \multicolumn{2}{|l|}{ Characteristics } \\
\hline$M: F$ & $30(70 \%): 13(30 \%)$ \\
\hline Mean (SD) age (years) & $41.4(10.1)$ \\
\hline Atopy positive:negative:unknown & $32(66 \%): 7$ (16\%):4 (9\%) \\
\hline Smoking S:ES:NS & $7(17 \%): 11(28 \%): 22(55 \%)$ \\
\hline Duration of exposure at work (years) & $13.6(11.2)$ \\
\hline Duration of work-related asthma symptoms (years) & $4.94(4.6)$ \\
\hline $\mathrm{FEV}_{1}(\%$ predicted $)$ & $97.8(17.0)$ \\
\hline $\mathrm{PC}_{20} \leqslant 16 \mathrm{mg} / \mathrm{ml}$ (n/total, \%) & $26 / 43 / 60.4$ \\
\hline $\mathrm{Vol}_{2-5}\left(\mathrm{~cm}^{3}\right)$ & $2.78(0.8)$ \\
\hline $\operatorname{MCA}\left(\mathrm{cm}^{2}\right)$ & $0.52(0.1)$ \\
\hline Molecular weight of suspected agents HMW:LMW & $21(49 \%): 22(51 \%)$ \\
\hline \multicolumn{2}{|l|}{$\begin{array}{l}\text { History of nasal symptoms: all }(n=40) \text {; HMW } \\
(n=18) \text {; LMW }(n=22)^{*}\end{array}$} \\
\hline Runny nose & $32(80 \%): 16(89 \%): 16(73 \%)$ \\
\hline Sneezing & $33(83 \%): 16(89 \%): 17(77 \%)$ \\
\hline Blocked nose & $29(73 \%): 14(78 \%): 15(68 \%)$ \\
\hline Itching & $29(73 \%): 14(78 \%): 15(68 \%)$ \\
\hline
\end{tabular}

Data are presented as $\mathrm{n}(\%)$ or mean (SD).

$\mathrm{ES}$, ex-smoker; $\mathrm{FEV}_{1}$, forced expiratory volume in $1 \mathrm{~s}$; HMW, high molecular weight; LMW, low molecular weight; MCA, minimum cross-sectional area; NS, non-smoker; $\mathrm{PC}_{20}$, concentration of methacholine that caused a $20 \%$ fall in $\mathrm{FEV}_{1} ; \mathrm{S}$, smoker; $\mathrm{Vol}_{2-5}$, nasal volume $2-5 \mathrm{~cm}$ into the nose.

${ }^{*}$ Number $(\%)$ of subjects reporting nasal symptoms in all subjects and based on the molecular weight of the suspected agent. Data from the questionnaire were not available for three subjects.
Table 2 also shows that, in 11 instances, there was a concomitant clinically significant nasal and bronchial reaction in the group challenged with HMW agents. The RR expressing the association in this group was 1.3 (95\% CI 0.8 to 2.7$)$. A joint significant nasal and bronchial reaction was observed in only two instances in the LMW group.

The number and nature of positive and negative SIC tests is shown in the online supplement together with a description of the results on bronchial hyperresponsiveness, atopy and correlation between acoustic rhinometry and nasal lavage changes during SIC.

\section{Nasal lavage}

Nasal lavage samples from 25 SIC tests were analysed; nasal lavage was not performed in all SIC tests due to unavailability of the technique $(n=8)$, subjects refused the test $(n=5)$ or they were not able to follow the instructions to collect the sample $(n=5)$. The analysis of nasal lavage samples performed in 25 SIC tests $(H M W=14, L M W=11)$ showed that the predominant cells at baseline on the control and active days were neutrophils and epithelial cells. There were no statistically significant differences in the percentage of neutrophils, macrophages and epithelial cells between the control and active days (data not shown). Lymphocytes were not analysed because only a few samples contained these cells and the number of cells was too low.

Table 3 shows that provocation with the control agent did not induce significant changes in the percentage of eosinophils on the control day in subjects with a final positive or negative nasal challenge. By contrast, provocation with the active agent resulted in a significant increase in the percentage of eosinophils in the subjects with a final positive nasal challenge 30 min after total exposure compared with baseline values and with values on the control day at the same challenge time. This increase was still apparent $6 \mathrm{~h}$ later, but without reaching statistical significance. There were no significant differences in the early and late eosinophilic response in the group of subjects with a final negative nasal challenge.

\section{DISCUSSION}

The results of this study with subjects referred for investigation of possible OA showed that OR can be assessed by objective means and that it frequently coexists with $\mathrm{OA}$ but can be present without $O A$. Taken together, the results provide further objective evidence in support of the UAD concept by using $\mathrm{OA}$ and $\mathrm{OR}$ as a model to demonstrate a parallel significant physiological reaction of the nose and lungs after challenge with occupational agents.

In the general population, rhinitis may be present in up to $80 \%$ of patients with asthma. ${ }^{21}$ In our study the association between $\mathrm{OR}$ and $\mathrm{OA}$ followed the same pattern, with $\mathrm{OR}$ occurring in $76.4 \%$ of confirmed cases of OA (table 2). SIC testing showed that a confirmed diagnosis of OR was more frequent than a confirmed diagnosis of $\mathrm{OA}$. These results underline the importance of using objective means in the investigation of $\mathrm{OR}$ in order to gain a more accurate perspective of the impact of this disease. They also point out the relevance of using means to also assess upper airways in the context of the assessment of OA.

A positive association between nasal and bronchial responses was observed after challenge with HMW and LMW agents. Our study demonstrated a concomitant significant decline in nasal patency and bronchial calibre in 13 of 43 SIC tests. The 
Table 2 Outcome of specific inhalation challenge (SIC) based on nasal and bronchial response and type of suspected agent

\begin{tabular}{|c|c|c|c|c|c|c|c|c|c|}
\hline \multirow[b]{3}{*}{ Group } & \multicolumn{3}{|c|}{ All SIC } & \multicolumn{3}{|c|}{ HMW } & \multicolumn{3}{|c|}{ LMW } \\
\hline & \multicolumn{3}{|c|}{ Low bronchial calibre* } & \multicolumn{3}{|c|}{ Low bronchial calibre* } & \multicolumn{3}{|c|}{ Low bronchial calibre* } \\
\hline & Yes & No & Total & Yes & No & Total & Yes & No & Total \\
\hline \multicolumn{10}{|c|}{$\begin{array}{l}\text { Low nasal airway } \\
\text { patency† }\end{array}$} \\
\hline Yes & 13 & 12 & 25 & 11 & 4 & 15 & 2 & 8 & 10 \\
\hline No & 4 & 14 & 18 & 4 & 3 & 7 & 0 & 11 & 11 \\
\hline Total & 17 & 26 & 43 & 15 & 7 & 22 & 2 & 19 & 21 \\
\hline $\mathrm{RR}(95 \% \mathrm{Cl})$ & \multicolumn{3}{|c|}{1.7 (1.0 to 2.4$)$} & \multicolumn{3}{|c|}{$1.3(0.8$ to 2.7$)$} & \multicolumn{3}{|c|}{$2.4(0.7$ to 2.4$)$} \\
\hline p Value & \multicolumn{3}{|c|}{0.04} & \multicolumn{3}{|l|}{0.6} & \multicolumn{3}{|l|}{0.2} \\
\hline
\end{tabular}

magnitude of the observed association was not marked, probably because of the small sample size. However, the observed changes allowed us to make an objective diagnosis of $\mathrm{OR}$ and $\mathrm{OA}$ in the same patient, supporting the applicability of the UAD model to rhinitis and asthma of occupational origin. A subanalysis based on the type of agent investigated showed that a clinically significant "united airways" response was more frequent for HMW agents than for LMW agents (table 2). However, the association of clinically significant nasal and bronchial responses in the HMW group did not reach statistical significance. These results need to be verified by further studies in a larger population because, although not statistically significant, they may represent a real effect.

Table 2 also shows that, when there is significant lower nasal patency, there is not necessarily any change in the calibre of the lower airways. Accordingly, the results showed that a diagnosis of OA was not made in 12 SIC tests and therefore OR was the sole diagnosis. This was independent of the type of causal agent (HMW or LMW). A "stepwise sensitisation" may occur where the nose-as the first line of defence-becomes sensitised first and then the sensitisation process progresses down the respiratory tract until it reaches the bronchi. According to this pattern, we would expect a gradual worsening of lower respiratory tract symptoms among those subjects with OR alone that may ultimately lead to a clear manifest $O A$ if exposure to the offending agent continues.

However, although the progression from OR to OA has been documented, ${ }^{22}$ it certainly does not occur in all circumstances, contrary to the hypothesis of the "allergic march" model. Occupational longitudinal epidemiological studies have failed to demonstrate a clear "allergic march". ${ }^{23}$ In the general population it is well established that only a proportion of patients with allergic rhinitis develop asthma. ${ }^{24}$ It is therefore realistic to speculate that more factors are involved in the pathogenesis and natural history of OR. An alternative or complementary hypothesis to explain the isolated expression of $\mathrm{OR}$ in some of our study subjects may entail an increased local production of immunoglobulin E (IgE) in the nose. It has been shown that the nasal and bronchial mucosa have the capability to induce an IgE-mediated immunological response. ${ }^{25}{ }^{26}$ Local production of IgE has been detected in nasal B cells of patients with allergic rhinitis. ${ }^{27}$ One study has shown that cultured functional nasal $\mathrm{B}$ cells are able to synthesise IgE. ${ }^{28}$

A similar hypothesis may explain isolated cases of $O A$. An increase in specific IgE in bronchoalveolar lavage fluid has been found after segmental allergen challenge in subjects with atopic asthma. ${ }^{29}$ In our study we did not observe a significant nasal reaction in 4/17 SIC tests showing a positive bronchial reaction in which, based on the UAD model, we would expect a reaction in both the nose and the bronchi. Two instances may be explained by the induction of an immediate bronchial reaction (at $20 \mathrm{~s}$ and $7 \mathrm{~min}$ after the start of the challenge) that precluded extended exposure. Although plausible, it seems unlikely; we do not know if the carryover of the exposure might have induced a significant reaction in the nose because, in all cases showing a positive nasal and bronchial reaction, the nose always reacted before the bronchi. The explanation for these two cases is yet to be determined.

Analogous to the examination of induced sputum in the investigation of $\mathrm{OA},{ }^{30}$ nasal lavage may have additional diagnostic value in the investigation of OR. Our results confirm findings from previous studies that showed that challenges with

Table 3 Change in percentage of eosinophils in nasal lavage fluid after exposure to control and active agents in subjects with a final positive or negative nasal challenge

\begin{tabular}{|c|c|c|c|c|c|c|c|}
\hline \multicolumn{4}{|c|}{ Nasal challenge } & \multicolumn{4}{|c|}{ Time of nasal lavage during SIC } \\
\hline & $\mathbf{n}$ & Agent & Before & 30 min post & p Value* & $6 \mathrm{~h}$ post & p Value $\dagger$ \\
\hline \multirow[t]{3}{*}{ Positive } & 15 & Control & $0.0(0.9)$ & $0.0(0.8)$ & 0.5 & $0.0(0.2)$ & 0.07 \\
\hline & 15 & Active & $0.0(0.8)$ & $0.2(5.2)$ & 0.03 & $0.2(2.8)$ & 0.2 \\
\hline & & $\mathrm{p}$ Value: & 0.2 & 0.02 & & 0.1 & \\
\hline \multirow[t]{3}{*}{ Negative } & 8 & Control & $0.7(1.2)$ & $0.3(2.2)$ & 0.7 & $0.3(0.5)$ & 0.7 \\
\hline & 9 & Active & $0.0(0.2)$ & $0.3(1.2)$ & 0.1 & $0.3(3.2)$ & 0.1 \\
\hline & & $\mathrm{p}$ Valuet: & 0.07 & 0.6 & & 0.4 & \\
\hline
\end{tabular}

Numbers represent median and interquartile range (IOR).

${ }^{*}$ Comparing values before and at $30 \mathrm{~min}$.

†Comparing values before and at $6 \mathrm{~h}$.

tComparing values on the control and active days. 
HMW and LMW agents can induce an influx of eosinophils in nasal lavage samples. ${ }^{31-33}$ We observed an increase in the percentage of eosinophils $\geqslant 3 \%$ in eight nasal lavage samples, five of which corresponded to cases with positive nasal and bronchial challenges. Analysis of nasal lavage samples also showed no changes in the percentage of eosinophils in some subjects who had a significant decrease in nasal patency after challenge. This finding may suggest an irritant rather than an inflammatory nasal response; however, these subjects tested negative during the control session after exposure to a nonspecific irritant. In addition, seven subjects in this group had an associated positive bronchial reaction after SIC testing, suggesting an allergic response. No increase in nasal eosinophil count was observed in subjects with an isolated positive bronchial response. We think these observations reflect different underlying pathogenic mechanisms that deserve further investigation. In line with other studies, ${ }^{31}$ no significant increase was seen in the proportion of neutrophils after challenge with either the control or active agent.

Based on our findings, assessment of inflammation of the upper airways by nasal lavage and assessment of nasal patency by acoustic rhinometry are complementary and therefore can be recommended for the investigation of OR.

Further investigations of $\mathrm{OR}$ in the context of the UAD model should focus on determining the pathogenic mechanisms involved in the expression of OR alone or in association with OA for the two categories of causal agent (HMW and LMW). Tests to characterise induced inflammation in the upper and lower airways and their association after exposure to HMW and LMW agents should also be carried out in a larger population.

Acknowledgements: $\mathrm{RC}$ is a research fellow supported by the Center for Asthma in the Workplace, a Canadian Institute of Health Research (ClHR), Centre for Research Development.

Competing interests: None.

Ethics approval: Ethical approval for the study was obtained from the hospital medical ethics committee.

\section{REFERENCES}

1. Chan-Yeung M, Malo JL. Occupational asthma. N Engl J Med 1995;333:107-12.

2. Malo JL, Lemiere C, Desjardins A, et al. Prevalence and intensity of rhinoconjunctivitis in subjects with occupational asthma. Eur Respir J 1997;10:15135 .

3. Karjalainen A, Martikainen R, Klaukka T, et al. Risk of asthma among Finnish patients with occupational rhinitis. Chest 2003;123:283-8.

4. Folletti I, Forcina A, Marabini A, et al. Have the prevalence and incidence of occupational asthma and rhinitis because of laboratory animals declined in the last 25 years? Allergy 2008;63:834-41.

5. Moscato G, Vandenplas 0, Gerth Van Wijk R, et al. Occupational rhinitis. Allergy 2008;63:969-80.

6. Vandenplas $\mathbf{0}$, Malo JL. Inhalation challenges with agents causing occupational asthma. Eur Respir J 1997:10:2612-29.

7. Airaksinen $\mathbf{L}$, Tuomi $T$, Vanhanen $\mathrm{M}$, et al. Use of nasal provocation test in the diagnostics of occupational rhinitis. Rhinology 2007;45:40-6.
8. Gosepath J, Amedee RG, Mann WJ. Nasal provocation testing as an international standard for evaluation of allergic and nonallergic rhinitis. Laryngoscope 2005;115:512-6.

9. Hytonen M, Sala E. Nasal provocation test in the diagnostics of occupational allergic rhinitis. Rhinology 1996;34:86-90.

10. Cloutier $\mathbf{Y}$, Lagier F, Cartier A, et al. Validation of an exposure system to particles for the diagnosis of occupational asthma. Chest 1992;102:402-7.

11. Malo JL, Cartier A, Lemiere C, et al. Exaggerated bronchoconstriction due to inhalation challenges with occupational agents. Eur Respir J 2004;23:300-3.

12. Malo JL, Ghezzo H, Elie R. Occupational asthma caused by isocyanates: patterns of asthmatic reactions to increasing day-to-day doses. Am J Respir Crit Care Med 1999;159:1879-83.

13. Hilberg 0, Pedersen OF. Acoustic rhinometry: recommendations for technical specifications and standard operating procedures. Rhinol Supp/ 2000;16:3-17.

14. Castano R, Theriault G, Gautrin D, et al. Reproducibility of acoustic rhinometry in the investigation of occupational rhinitis. Am J Rhinol 2007;21:474-7.

15. Naclerio RM, Meier HL, Kagey-Sobotka A, et al. Mediator release after nasal airway challenge with allergen. Am Rev Respir Dis 1983;128:597-602.

16. Castano R, Theriault G, Maghni K, et al. Reproducibility of nasal lavage in the context of the inhalation challenge investigation of occupational rhinitis. Am J Rhinol 2008;22:271-5.

17. Perrin LF, Dechamp C, Deviller $P$, et al. Reproducibility of skin tests. A comparative study of the Pepys prick test and the Morrow-Brown needle and their correlation with the serum IgE level. Clin Allergy 1984;14:581-8.

18. GansImayer M, Spertini F, Rahm F, et al. Evaluation of acoustic rhinometry in a nasal provocation test with allergen. Allergy 1999;54:974-9.

19. Pirila T, Nuutinen J. Acoustic rhinometry, rhinomanometry and the amount of nasal secretion in the clinical monitoring of the nasal provocation test. Clin Exp Allergy 1998;28:468-77.

20. Vandenplas 0, Cartier A, Malo JL. Occupational challenge tests. In: Bernstein I, Chan-Yeung M, Malo JL, Bernstein D, eds. Asthma in the workplace. New York: Taylor \& Francis, 2006:227-52.

21. Leynaert B, Neukirch F, Demoly P, et al. Epidemiologic evidence for asthma and rhinitis comorbidity. J Allergy Clin Immunol 2000;106(5 Suppl):S201-5.

22. Piirila $\mathbf{P}$, Estlander $\mathrm{T}$, Hytonen $\mathrm{M}$, et al. Rhinitis caused by ninhydrin develops into occupational asthma. Eur Respir J 1997;10:1918-21.

23. Walusiak J, Hanke W, Gorski $\mathrm{P}$, et al. Respiratory allergy in apprentice bakers: do occupational allergies follow the allergic march? Allergy 2004;59:442-50.

24. Bousquet J, Vignola AM, Demoly P. Links between rhinitis and asthma. Allergy 2003;58:691-706.

25. Durham SR, Gould HJ, Hamid QA. Local lgE production in nasal allergy. Int Arch Allergy Immunol 1997;113:128-30.

26. Fokkens WJ, Vinke JG, KleinJan A. Local IgE production in the nasal mucosa: a review. Am J Rhinol 2000;14:299-303.

27. KleinJan A, Vinke JG, Severijnen LW, et al. Local production and detection of (specific) IgE in nasal B-cells and plasma cells of allergic rhinitis patients. Eur Respir J 2000;15:491-7.

28. Zurcher AW, Derer $\mathrm{T}$, Lang $\mathrm{AB}$, et al. Culture and IgE synthesis of nasal $\mathrm{B}$ cells. Int Arch Allergy Immunol 1996;111:77-82.

29. Wilson DR, Merrett TG, Varga EM, et al. Increases in allergen-specific IgE in BAL after segmental allergen challenge in atopic asthmatics. Am J Respir Crit Care Med 2002:165:22-6

30. Girard F, Chaboillez S, Cartier A, et al. An effective strategy for diagnosing occupational asthma: use of induced sputum. Am J Respir Crit Care Med 2004;170:845-50.

31. Krakowiak A, Ruta U, Gorski P, et al. Nasal lavage fluid examination and rhinomanometry in the diagnostics of occupational airway allergy to laboratory animals. Int J Occup Med Environ Health 2003;16:125-32.

32. Palczynski C, Walusiak J, Ruta U, et al. Occupational asthma and rhinitis due to glutaraldehyde: changes in nasal lavage fluid after specific inhalatory challenge test. Allergy 2001;:56:1186-91.

33. Palczynski C, Walusiak J, Krakowiak $A$, et al. Nasal lavage fluid examination in diagnostics of occupational allergy to chloramine. Int J Occup Med Environ Health 2003; 16:231-40. 